\title{
Microhemorrhagic transformation of ischemic lesions on T2*-weighted magnetic resonance imaging after Pipeline embolization device treatment
}

\author{
Ryuta Nakae, MD, PhD, Masaya Nagaishi, MD, PhD, Yosuke Kawamura, MD, \\ Yoshihiro Tanaka, MD, Akio Hyodo, MD, PhD, and Kensuke Suzuki, MD, PhD \\ Department of Neurosurgery, Dokkyo Medical University Saitama Medical Center, Saitama, Japan
}

OBJECTIVE The authors sought to demonstrate that hemorrhagic transformation of ischemic lesions is the main cause of delayed intracerebral hemorrhage (ICH) after Pipeline embolization device (PED) treatment and to estimate the rate of hemorrhagic transformation of new postprocedure ischemic lesions.

METHODS Patients who underwent PED placement (PED group) from November 2015 to March 2017 or stent-mediated embolization (EN group) from December 2010 to October 2015 were retrospectively analyzed. Pre- and postprocedural MR images and 6-month follow-up MR images for each patient were scored for the presence of postprocedural bland ischemic and hemorrhagic lesions using diffusion-weighted MRI (DWI) and T2* ${ }^{*}$ weighted MRI (T2* WI), respectively.

RESULTS The PED group comprised 28 patients with 30 intracranial aneurysms, and the EN group comprised 24 patients with 27 intracranial aneurysms. The mean number of ischemic lesions on DWI 1 day postprocedure was higher in the PED group than in the EN group (5.2 vs 2.7, $p=0.0010$ ). The mean number of microbleeds detected on T2* WI 6 months postprocedure was higher in the PED group than in the EN group ( 0.6 vs $0.15, p=0.028$ ). A total of $36.7 \%$ of PED-treated patients exhibited new microbleeds on T2* WI at 6 months postprocedure, with at least $77.8 \%$ of these lesions representing hemorrhagic transformations of the new ischemic lesions observed on day 1 postprocedure. The rate of adjunctive coil embolization $(27.3 \%$ vs $0.0 \%, p=0.016)$ and the mean number of ischemic lesions observed 1 day postprocedure (6.6 vs $4.3, p=0.020$ ) were predictors of subsequent microbleeds in the PED group.

CONCLUSIONS New microbleeds detected using T2* WI at 6 months postprocedure were more common after PED treatment than after stent-mediated embolization. Approximately three-quarters of these lesions were hemorrhagic transformations of new ischemic lesions observed on day 1 postprocedure. Prevention of intraprocedural or postprocedural infarcts is necessary to reduce the risk of hemorrhagic complications following PED placement.

https://thejns.org/doi/abs/10.3171/2017.12.JNS172480

KEYWORDS intracranial aneurysm; intracranial hemorrhage; brain infarction; magnetic resonance imaging; stents; interventional neurosurgery

$\mathrm{F}$ LOw diverters (FDs) have become an increasingly preferred alternative for the intravascular treatment of intracranial aneurysms. ${ }^{1,24}$ These stents have low porosity and are inserted into the parent artery to guide blood flow away from the aneurysm ${ }^{22}$ and to encourage thrombosis of the aneurysm and neointimal overgrowth of the aneurysm neck. ${ }^{17} \mathrm{FD}$ treatment is especially recommended for large/giant, wide-necked, and fusiform aneurysms. ${ }^{1}$

Symptomatic delayed intracerebral hemorrhage (ICH) is a severe complication of FD treatment. Several studies have reported delayed ipsilateral ICH following treatment with the Pipeline embolization device (PED, Covidi- en). $3,4,6,7,11,15,34$ These studies all reported normal recovery of patients from general anesthesia, followed by subsequent development of delayed neurological deterioration after the occurrence of ICH in the distal region supplied by the stented artery hours to days postprocedure. In the Pipeline for Uncoilable or Failed Aneurysms (PUFS) trial, ${ }^{1}$ ICH was observed in 5 of 107 patients $(4.7 \%)$ and was linked to ischemia, trauma, and warfarin use. The Pipeline Embolization Device for the Intracranial Treatment of Aneurysms (PITA) trial ${ }^{24}$ did not result in delayed ICH in any of the 31 treated patients. As neither of these two trials used routine postoperative brain imaging, minor or asymptomatic ICH

ABBREVIATIONS DWI = diffusion-weighted MRI; EN = Enterprise or Neuroform; FD = flow diverter; ICH = intracerebral hemorrhage; mRS = modified Rankin Scale; PED = Pipeline embolization device; $\mathrm{T} 2^{*} \mathrm{WI}=\mathrm{T} 2^{*}$-weighted MRI.

SUBMITTED October 16, 2017. ACCEPTED December 19, 2017.

INCLUDE WHEN CITING Published online June 1, 2018; DOI: 10.3171/2017.12.JNS172480. 
may have gone undetected. We hypothesized that hemorrhagic transformation of postprocedural bland ischemic lesions is the main cause of delayed ICH following PED treatment and that PED-treated patients might have an increased risk of hemorrhagic transformation compared with those treated with standard stent-assisted coiling methods. This hypothesis is based on several reports showing that PED treatment is correlated with a higher rate of ipsilateral ischemic lesions on diffusion-weighted MRI (DWI) compared with conventional stent-assisted coiling methods. ${ }^{13,14,16}$ Some of these lesions may progress to massive hemorrhages with neurological deterioration.

T2*-weighted MRI (T2*WI) has proven more sensitive for detecting cerebral microbleeds as hypointense lesions than have CT and other MRI methods. ${ }^{5,12,21,27}$ Cerebral microbleeds are considered a potential risk factor for more extensive cerebral bleeding. ${ }^{2,10}$ The occurrence of hemorrhagic transformation of ischemic lesions following PED treatment may be detectable by $\mathrm{T} 2 * \mathrm{WI}$ in previously infarcted foci. It has not been clear whether new microbleeds occur in microinfarcts appearing postprocedure or in other locations. Here, we analyzed pre- and posttreatment images and the rate of delayed microbleeds demonstrated on T2*WI in patients treated with PED and conventional stent devices.

\section{Methods \\ Patient Population}

We retrospectively reviewed the demographic, clinical, and radiological characteristics of 28 consecutive patients who underwent PED placement (PED group) at our hospital from November 2015 to March 2017. According to the Japanese government approval of the PED, we included patients who had presented with an unruptured intracranial aneurysm of $\geq 10 \mathrm{~mm}$ in maximum diameter with a neck of $\geq 4 \mathrm{~mm}$ occurring between the petrous and superior hypophyseal segments and proximal to the posterior communicating segment of the internal carotid artery. Patients with recanalized aneurysms who required re-treatment after a previous embolization were also included. In addition, the imaging data of 24 consecutive patients who underwent stent-mediated embolization (Enterprise, Codman and Shurtleff; or Neuroform, Stryker) (EN group) at our institution between December 2010 and October 2015 were included for comparison. The inclusion criteria for the target aneurysms of the comparison group were the same as those for the PED group. We collected data on patient age; sex; comorbidities, including hypertension, diabetes mellitus, hyperlipidemia, and smoking status; maximum aneurysm diameter and neck diameter; type of stent; instances of coil embolization; procedure time (incision to stent placement, balloon angioplasty, or coil embolization, whichever was later); and modified Rankin Scale $(\mathrm{mRS})^{33}$ score $(0=$ asymptomatic; $6=$ death $)$ at 6 months postprocedure. This study was approved by the hospital's institutional review board.

\section{Patient Assessment}

All patients underwent catheter-based cerebral angi- ography conducted using the Siemens Artis zee system (Siemens Healthineers) (through February 2014) or the Siemens Artis Q system (beginning in March 2014). Aneurysm measurements were obtained from pretreatment digital subtraction angiography and 3D rotational angiography studies. The aneurysm neck was defined as the largest diameter along any plane at the junction with the parent artery. All patients were pretreated with aspirin (100 mg per day orally for 7 days) and clopidogrel (75 mg per day orally for 7 days). Aspirin reaction units (ARUs) and P2Y12 reaction units (PRUs) were calculated using the rapid platelet function assay VerifyNow (Accumetrics, Inc.) to determine aspirin and clopidogrel resistance. An abnormal antiplatelet response was defined as $>550$ ARUs and/or > 240 PRUs. ${ }^{8,18,25}$ The aspirin or clopidogrel dose was increased, or cilostazole (200 mg per day) was prescribed, when resistance was detected. Patients in both groups continued to receive aspirin and clopidogrel therapy for at least 6 months following treatment.

One endovascular neurosurgeon (A.H.) conducted all surgical procedures, which were performed under general anesthesia. After securing arterial access, patients were administered intravenous heparin to obtain a 250 -second activated clotting time. In the PED group, balloon angioplasty was performed if PED expansion was inadequate. Adjunctive coils were used via a jailed microcatheter after PED placement in cases of high inflow into the intracranial aneurysm, which is thought to be a risk factor for postprocedural rupture. ${ }^{20,26}$ Appropriate wall apposition of stents was assessed using multiplanar reconstructed dynamic CT imaging.

\section{MRI Review}

All patients underwent MRI using the Siemens MAGNETOM Avanto 1.5-T MRI system (Siemens Healthineers) (through March 2014) or the Siemens MAGNETOM Skyra 3-T MRI system (beginning in April 2014). MRI scans, including DWI and T2*WI pretreatment and 24-36 hours posttreatment, were routinely obtained in both groups. Patients were scheduled for a 6-month followup. Three patients whose follow-up MRI studies could not be obtained were excluded. The pre- and postembolization MRI and 6-month follow-up MRI studies for each patient were independently scored by 2 reviewers (R.N. and Y.K.) for the presence of procedure-related DWI and T2*WI lesions, and the absolute values of the number of DWI and T2*WI lesions on each MRI study were noted (Figs. 1 and 2). On each follow-up MRI study, only new T2*WI lesions that were not present on the preprocedural MRI study were scored.

\section{Statistical Analysis}

Analysis was conducted using commercial software (IBM SPSS, version 24.0, IBM Corp.). Demographic, clinical, and radiological parameters for the 2 groups were analyzed using the Student t-test, Mann-Whitney U-test, or chi-square test for continuous normally distributed, continuous nonnormally distributed, and dichotomous data, respectively. Statistical significance was defined as $p<0.05$. 

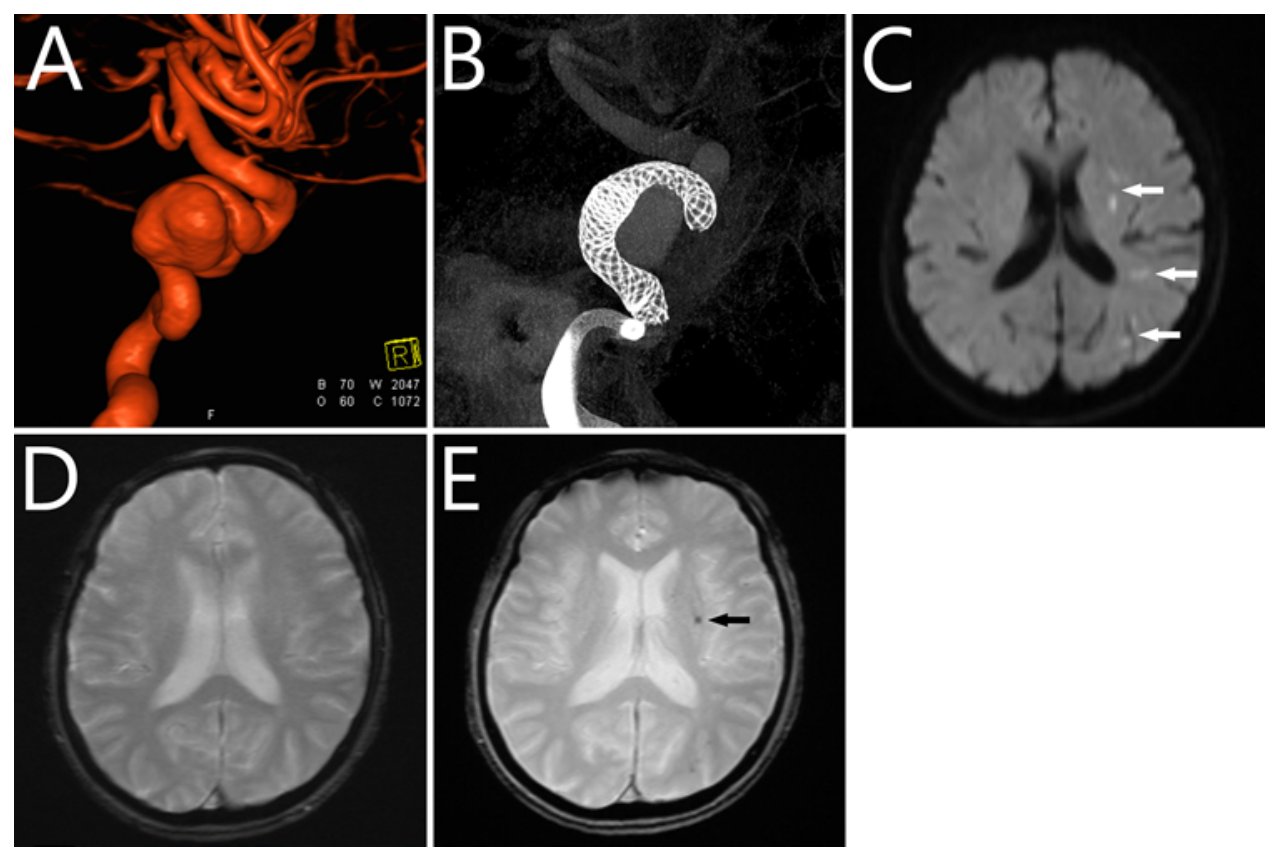

FIG. 1. A: Lateral 3D rotational angiogram revealing a large intracranial aneurysm measuring $20.2 \times 12.2 \mathrm{~mm}$ located in the cavernous segment of the left internal carotid artery. B: Multiplanar reconstructed dynamic CT scan obtained postprocedure with dilute contrast injection, showing the deployed PED traversing the neck of the aneurysm. C: DWI study obtained 1 day postprocedure, revealing hyperintense lesions in the left putamen and parietal lobe (arrows). D: T2*Wl study obtained 1 day postprocedure, revealing no hypointense lesions. E: T2*WI study obtained 6 months postprocedure, revealing a hemorrhagic lesion (asymptomatic) in the left putamen (arrow) in the same infarcted area as that observed on postprocedural DWI. Figure is available in color online only.
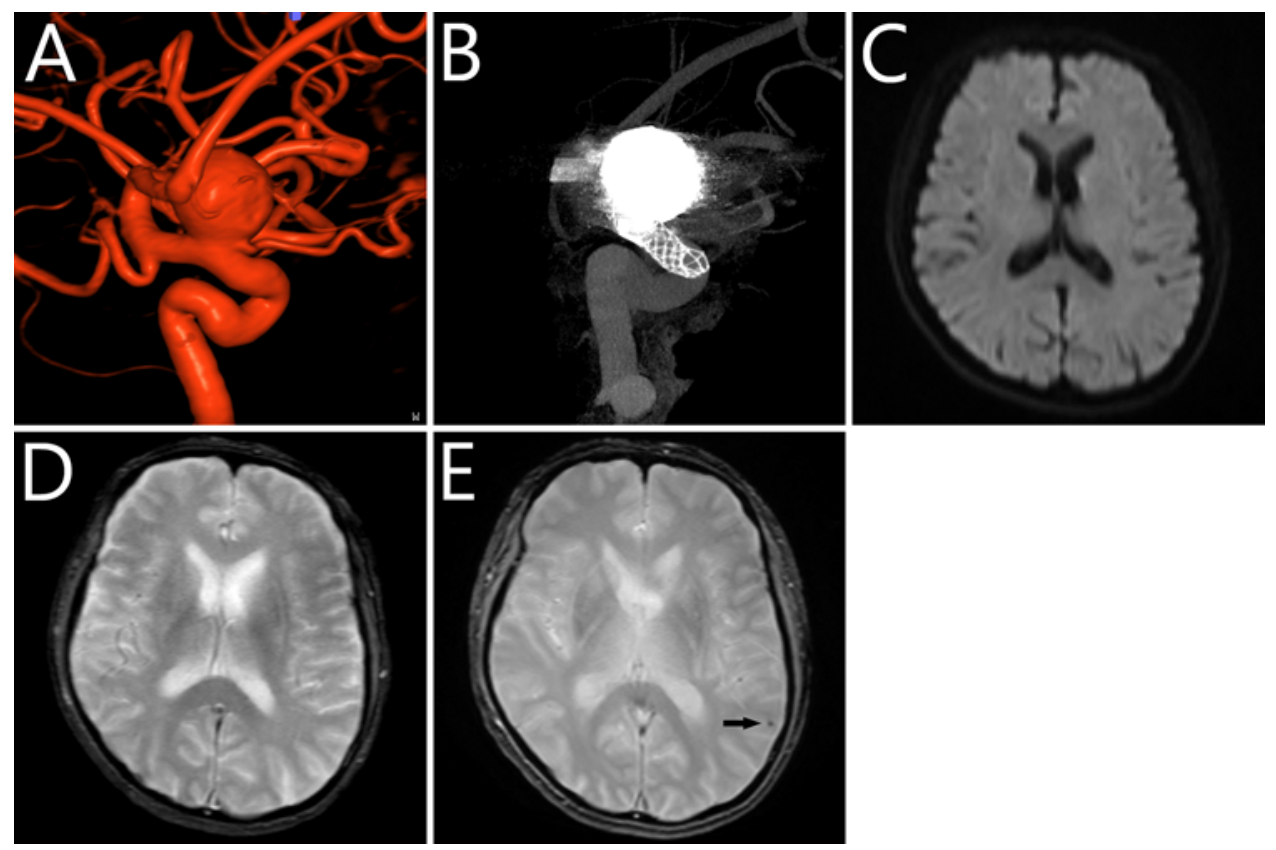

FIG. 2. A: Lateral 3D rotational angiogram revealing a large intracranial aneurysm measuring $14.0 \times 11.8 \mathrm{~mm}$ located in the superior hypophyseal segment of the left internal carotid artery. B: Multiplanar reconstructed dynamic CT scan with diluted contrast obtained postprocedure, showing the deployed PED traversing the neck of the aneurysm with adjunctive coils. C: DWI study obtained 1 day postprocedure, revealing no hyperintense lesions. D: T2*Wl study obtained 1 day postprocedure, revealing no hypointense lesions. E: T2*Wl study obtained 6 months postprocedure, revealing a hemorrhagic lesion (asymptomatic) in the left temporoparietal lobe (arrow). Figure is available in color online only. 
TABLE 1. Summary of demographic, clinical, and radiological characteristics

\begin{tabular}{|c|c|c|c|}
\hline & PED Group & EN Group & $p$ Value \\
\hline No. of patients & 28 & 24 & \\
\hline No. of aneurysms & 30 & 27 & \\
\hline Mean age, yrs & $62.8 \pm 10.7$ & $61.2 \pm 10.3$ & 0.58 \\
\hline Sex & & & 0.21 \\
\hline Male & $3(10.0)$ & $6(22.2)$ & \\
\hline Female & $27(90.0)$ & $21(77.8)$ & \\
\hline HTN & $23(76.7)$ & $17(63.0)$ & 0.26 \\
\hline DM & $5(16.7)$ & $2(7.4)$ & 0.29 \\
\hline $\mathrm{HL}$ & $10(33.3)$ & $4(14.8)$ & 0.10 \\
\hline Smoking & $7(23.3)$ & $2(7.4)$ & 0.10 \\
\hline \multicolumn{4}{|l|}{ Aneurysm size, mm } \\
\hline Mean maximum diameter & $18.9 \pm 10.4$ & $15.4 \pm 6.4$ & 0.12 \\
\hline Mean neck diameter & $7.0 \pm 2.3$ & $7.9 \pm 3.2$ & 0.23 \\
\hline \multicolumn{4}{|l|}{ Type of stent } \\
\hline PED & $30(100.0)$ & $0(0.0)$ & \\
\hline Enterprise & $0(0.0)$ & $22(81.5)$ & \\
\hline Neuroform & $0(0.0)$ & $5(18.5)$ & \\
\hline Coil embolization & $3(10.0)$ & $27(100.0)$ & $<0.0001$ \\
\hline Mean procedure time, mins & $82.2 \pm 32.8$ & $143.0 \pm 44.0$ & $<0.0001$ \\
\hline $\begin{array}{l}\text { mRS score at } 6 \text { mos post- } \\
\text { procedure }\end{array}$ & & & 0.29 \\
\hline $0-2$ & $30(100.0)$ & $26(96.3)$ & \\
\hline $3-5$ & $0(0.0)$ & $1(3.7)$ & \\
\hline
\end{tabular}

$\mathrm{DM}=$ diabetes mellitus; $\mathrm{HL}=$ hyperlipidemia; $\mathrm{HTN}=$ hypertension.

Values represent the number of patients or aneurysms (\%) unless otherwise specified. Mean values are presented as the mean \pm SD.

\section{Results}

\section{Patient Characteristics}

Demographic, clinical, and radiological characteristics of patients are summarized in Table 1 . The PED group comprised 28 patients with 30 intracranial aneurysms. The EN group comprised 24 patients with 27 intracranial aneurysms. Age; sex; presence of hypertension, diabetes mellitus, or hyperlipidemia; smoking status; maximum aneurysm diameter; and aneurysm neck diameter were comparable between the groups. The mean procedure time was shorter in the PED group than in the EN group (82.2 minutes vs 143 minutes, $p<0.0001$ ). There was no significant difference in mRS score at 6 months postprocedure between the groups.

\section{MRI Findings 1 Day Postprocedure}

The mean number of new ischemic lesions detected on DWI 1 day postprocedure was higher in the PED group than the EN group (5.2 vs 2.7, $\mathrm{p}=0.0010)$. No microbleeds were observed on $\mathrm{T} 2 * \mathrm{WI}$ on day 1 postprocedure in either the PED or EN group (Table 2).

\section{MRI Findings 6 Months Postprocedure}

The prevalence of microbleeds detected on T2*WI at 6 months postprocedure was significantly higher in the PED group than in the EN group $(36.7 \%$ vs $11.1 \%$, p = 0.025; Table 2). All microbleeds were asymptomatic. The mean number of microbleeds per patient at 6 months postprocedure was also higher in the PED group than in the EN group ( 0.6 vs $0.15, p=0.028)$. All microbleeds were observed distal to the stented artery. All microbleeds in the EN group were observed in the same infarcted area as that noted on DWI performed 1 day postprocedure, while $22.2 \%$ of microbleeds in the PED group were found distant from DWI bland lesions observed 1 day postprocedure; however, there was no significant difference between the groups.

\section{Predictors of Microbleeds}

We evaluated predictors of microbleeds by comparing patients with and without microbleeds at 6 months postprocedure (Table 3). The use of PEDs (78.6\% vs $44.2 \%$, p $=0.025)$, the overall rate of ischemic lesions observed on DWI 1 day postprocedure $(100.0 \%$ vs $74.4 \%, p=0.035)$, and the mean number of ischemic lesions per patient (5.9 vs $3.3, p=0.0042$ ) were higher in patients with, compared with those without, microbleeds.

\section{Predictors of Microbleeds in the PED Group}

We evaluated predictors of microbleeds in the PED group by comparing patients with and without microbleeds at 6 months postprocedure (Table 4). The rate of adjunctive coil embolization was significantly higher in patients with, compared with those without, microbleeds $(27.3 \%$ vs $0.0 \%$, $\mathrm{p}=0.016$ ). While the overall rate of ischemic lesions ob-

TABLE 2. Summary of radiographic outcomes

\begin{tabular}{lccc}
\hline & PED Group & EN Group & p Value \\
\hline No. of aneurysms & 30 & 27 & 0.061 \\
\hline Ischemic lesions on DWI 1 day postprocedure & $27(90.0)$ & $19(70.4)$ & 0.0010 \\
\hline Mean no. of ischemic lesions (range) & $5.2(0-9)$ & $2.7(0-7)$ & 0.025 \\
\hline Microbleeds on T2*WI at 1 day postprocedure & $0(0.0)$ & $0(0.0)$ & 0.028 \\
\hline Microbleeds on T2*Wl at 6 mos postprocedure & $11(36.7)$ & $3(11.1)$ & $0.15(0-2)$ \\
\hline Mean no. of microbleeds (range) & $0.6(0-5)$ & 4 & 0.30 \\
\hline Total no. of microbleeds & 18 & $4(100.0)$ & $0(0.0)$ \\
\hline Located in the same area as the ischemic lesion & $14(77.8)$ & $4(22.2)$ & \\
\hline Located in a different area from the ischemic lesion & &
\end{tabular}

Values represent the number of aneurysms (\%) unless otherwise specified. Mean values are presented as the mean \pm SD. 
TABLE 3. Univariate analysis of patients with or without new microbleeds on $\mathrm{T} 2^{*} \mathrm{Wl}$ imaging at 6 months postprocedure

\begin{tabular}{|c|c|c|c|}
\hline & $\begin{array}{l}\text { Patients } \\
\text { w/ New } \\
\text { Microbleeds } \\
\text { at } 6 \text { Mos }\end{array}$ & $\begin{array}{l}\text { Patients } \\
\text { w/ No New } \\
\text { Microbleeds } \\
\text { at } 6 \text { Mos }\end{array}$ & $\begin{array}{c}\mathrm{p} \\
\text { Value }\end{array}$ \\
\hline No. of patients & 13 & 41 & \\
\hline No. of aneurysms & 14 & 43 & \\
\hline Mean age, yrs & $58.6 \pm 6.8$ & $63.2 \pm 11.2$ & 0.07 \\
\hline Sex & & & 0.51 \\
\hline Male & $3(21.4)$ & $6(14.0)$ & \\
\hline Female & $11(78.6)$ & $37(86.0)$ & \\
\hline HTN & $9(64.3)$ & $31(72.1)$ & 0.58 \\
\hline DM & $2(14.3)$ & $5(11.6)$ & 0.79 \\
\hline $\mathrm{HL}$ & $3(21.4)$ & $11(25.6)$ & 0.75 \\
\hline Smoking & $4(28.6)$ & $5(11.6)$ & 0.13 \\
\hline \multicolumn{4}{|l|}{ Aneurysm size, $\mathrm{mm}$} \\
\hline Mean maximum diameter & $19.8 \pm 12.7$ & $16.4 \pm 7.2$ & 0.41 \\
\hline Mean neck diameter & $6.9 \pm 2.5$ & $7.6 \pm 2.9$ & 0.67 \\
\hline Type of stent & & & 0.025 \\
\hline PED & $11(78.6)$ & $19(44.2)$ & \\
\hline Enterprise or Neuroform & $3(21.4)$ & $24(55.8)$ & \\
\hline Coil embolization & $6(42.9)$ & $24(55.8)$ & 0.40 \\
\hline Mean procedure time, mins & $108.5 \pm 47.4$ & $111.9 \pm 49.9$ & 0.88 \\
\hline $\begin{array}{l}\text { Ischemic lesions on DWI } 1 \\
\text { day postprocedure }\end{array}$ & $14(100.0)$ & $32(74.4)$ & 0.035 \\
\hline $\begin{array}{l}\text { Mean no. of ischemic } \\
\text { lesions } 1 \text { day post- } \\
\text { procedure }\end{array}$ & $5.9 \pm 2.6$ & $3.3 \pm 2.6$ & 0.0042 \\
\hline
\end{tabular}

Values represent the number of patients or aneurysms (\%) unless otherwise specified. Mean values are presented as the mean \pm SD.

served on DWI 1 day postprocedure did not differ between patients with and without microbleeds, the mean number of ischemic lesions per patient was higher in patients with microbleeds (6.6 vs $4.3, \mathrm{p}=0.020)$.

\section{Discussion}

We found that the mean number of ischemic lesions observed on DWI 1 day postprocedure was higher in the PED group than in the EN group. The mean number of microbleeds observed on T2*WI 6 months postprocedure was also higher in the PED group than in the EN group. A total of $36.7 \%$ of PED-treated patients had new microbleeds according to T2*WI 6 months postprocedure, with at least $77.8 \%$ of these being hemorrhagic transformations of ischemic lesions observed on day 1 postprocedure.

Several studies have shown that embolic risk is significantly increased with FD use compared with conventional stent-assisted coiling. ${ }^{13,14,16}$ Iosif et al. reported that 35 of 38 consecutive patients (92.1\%) showed at least one new hyperintense lesion on postprocedural DWI within the first 48 hours of PED treatment. ${ }^{16}$ This is consistent with our findings, where 27 of $30(90.0 \%)$ patients treated with PED showed hyperintense lesions on postprocedural DWI. Several studies have suggested that delayed ipsilat-
TABLE 4. Univariate analysis of patients treated with the PED with or without new microbleeds on T2* WI at 6 months postprocedure

\begin{tabular}{|c|c|c|c|}
\hline & $\begin{array}{c}\text { Patients } \\
\text { w/ New } \\
\text { Microbleeds } \\
\text { at } 6 \text { Mos }\end{array}$ & $\begin{array}{l}\text { Patients } \\
\text { w/ No New } \\
\text { Microbleeds } \\
\text { at } 6 \text { Mos }\end{array}$ & $\begin{array}{c}p \\
\text { Value }\end{array}$ \\
\hline No. of patients & 10 & 19 & \\
\hline No. of aneurysms & 11 & 19 & \\
\hline Mean age, yrs & $58.9 \pm 7.8$ & $65.4 \pm 11.5$ & 0.082 \\
\hline Sex & & & 0.26 \\
\hline Male & $2(18.2)$ & $1(5.3)$ & \\
\hline Female & $9(81.8)$ & $19(94.7)$ & \\
\hline HTN & $8(72.7)$ & $15(78.9)$ & 0.70 \\
\hline DM & $2(18.2)$ & $3(15.8)$ & 0.87 \\
\hline $\mathrm{HL}$ & $3(27.3)$ & $7(36.8)$ & 0.59 \\
\hline Smoking & $4(36.4)$ & $3(15.8)$ & 0.20 \\
\hline \multicolumn{4}{|l|}{ Aneurysm size, $\mathrm{mm}$} \\
\hline Mean maximum diameter & $21.2 \pm 13.8$ & $17.5 \pm 7.9$ & 0.48 \\
\hline Mean neck diameter & $7.0 \pm 1.9$ & $7.0 \pm 2.6$ & 0.96 \\
\hline Coil embolization & $3(27.3)$ & $0(0.0)$ & 0.016 \\
\hline Mean procedure time, mins & $91.7 \pm 34.8$ & $76.7 \pm 31.2$ & 0.28 \\
\hline $\begin{array}{l}\text { Ischemic lesions on DWI } 1 \text { day } \\
\text { postprocedure }\end{array}$ & $11(100.0)$ & $16(84.2)$ & 0.16 \\
\hline $\begin{array}{l}\text { Mean no. of ischemic lesions } \\
1 \text { day postprocedure }\end{array}$ & $6.6 \pm 2.3$ & $4.3 \pm 2.6$ & 0.020 \\
\hline
\end{tabular}

Values represent the number of patients or aneurysms (\%) unless otherwise specified. Mean values are presented as the mean \pm SD.

eral ICH may be a potential complication of FD treatment of intracranial aneurysms. $3,4,6,7,11,15,34$ The pathophysiology of this condition is unknown. Brinjikji et al. ${ }^{3}$ showed that ICH incidence increased 4-fold after treatment with multiple PEDs due to secondary hemorrhagic transformation of the resulting ischemic infarcts, which may arise from the exposure of platelets to a much greater surface area of metal. Our findings indicate that the number of new bland ischemic lesions detected on DWI 1 day postprocedure is predictive of subsequent microbleeds in patients treated with FDs. This in turn suggests that an intraprocedural or postprocedural infarction, which may have occurred as a result of thrombus formation on the stent with subsequent embolization, can cause delayed ICH. While most patients with hemorrhagic transformation of ischemic lesions show no obvious signs of clinical deterioration, hemorrhage expansion can exacerbate neurovascular damage and may result in symptomatic ICH. Considering that $36.7 \%$ of PEDtreated patients in the present study had new microbleeds detected on T2*WI 6 months postprocedure, it may be pertinent to control perioperative blood pressure to lower the risk of hemorrhagic transformation and subsequent expansion of ischemic lesions.

We also found that $22.2 \%$ of microbleeds in the PED group 6 months postprocedure occurred in areas distant from DWI lesions observed on day 1 postprocedure. Safain et al..$^{28}$ demonstrated an association between PED and 

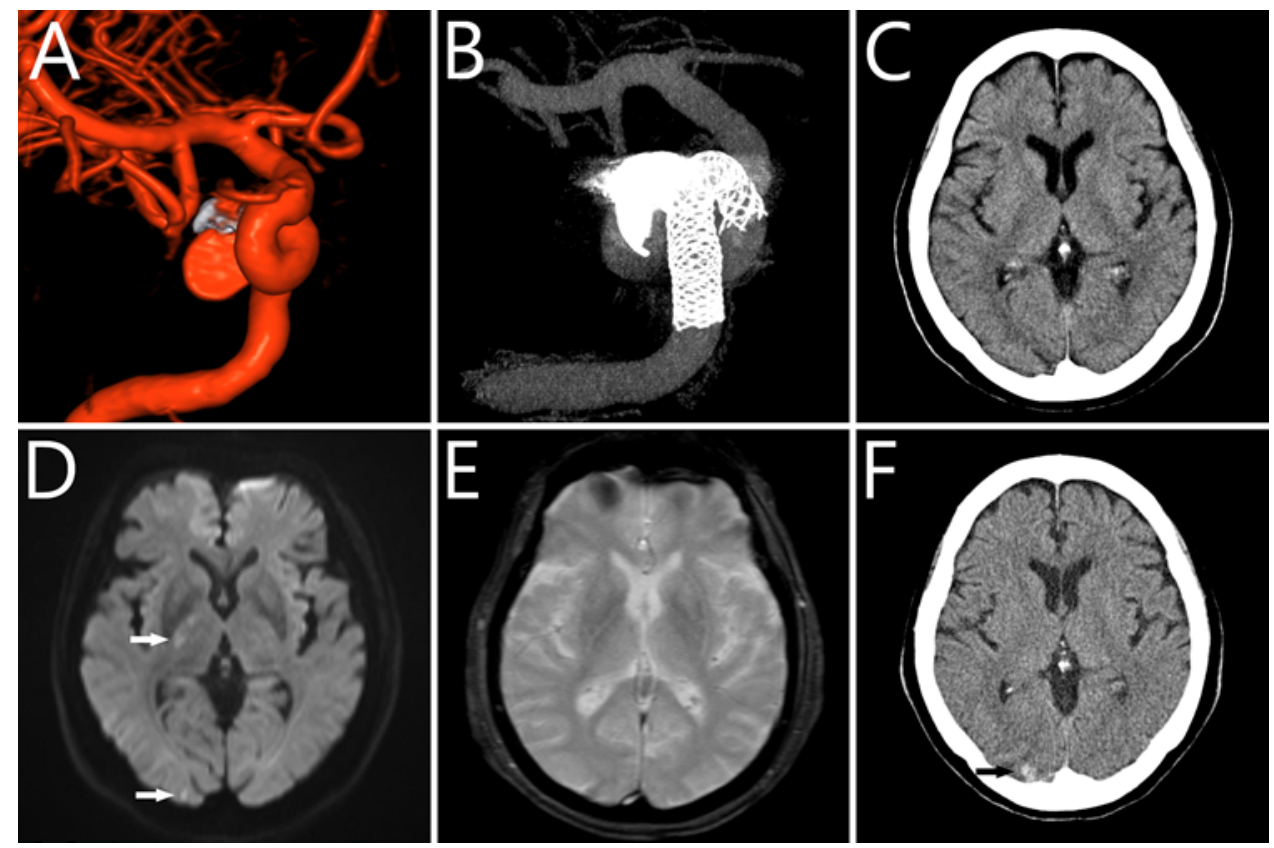

FIG. 3. A: Anterior 3D rotational angiogram revealing a large and partially thrombosed intracranial aneurysm measuring $13.0 \times 9.0$ $\mathrm{mm}$ after a previous embolization, located in the cavernous segment of the right internal carotid artery. B: Multiplanar reconstructed dynamic CT scan with diluted contrast obtained postprocedure, showing the deployed PED traversing the neck of the aneurysm. C: CT scan obtained 1 day postprocedure, revealing no abnormal foci. D: DWI study obtained 1 day postprocedure, revealing hyperintense lesions in the right internal capsule and occipital lobe (arrows). E: T2*WI study obtained 1 day postprocedure, revealing no hypointense lesion. F: CT scan obtained 7 days postprocedure, revealing an intracerebral hemorrhage in the right occipital lobe (arrow) in the same infarcted area as that observed on postprocedural DWI. Figure is available in color online only.

continued new and independent ipsilateral FLAIR signal abnormalities on MRI $\leq 1$ year after PED treatment. These lesions were not associated with any previous abnormalities identified on DWI or FLAIR, suggesting that they may have been delayed ischemic events and were most likely embolic from the stent/aneurysm complex. In the present study, 2 asymptomatic delayed ICHs located distal to the stented artery were detected in the PED group on CT performed 6 and 7 days postprocedure. One was detected in the same infarcted area as that observed on DWI 1 day postprocedure (Fig. 3), and the other was detected in an area different from that of the bland infarcted area observed on DWI 1 day postprocedure (Fig. 4). ${ }^{23}$ We propose that in the latter case, hemorrhagic transformation of an embolic infarction that occurred $>2$ days postprocedure may have been the cause of delayed ICH.

Dual antiplatelet therapy is a common cause of hemorrhagic complications. The annual risk of major ICH with dual antiplatelet therapy for secondary stroke prevention is $1.1 \%-1.8 \% .9,29$ The hemorrhagic risk of stent-assisted coiling of unruptured intracranial aneurysms with dual antiplatelet therapy is $2.2 \%-2.6 \% .{ }^{19,30} \mathrm{Sim}$ et al.$^{31}$ showed that the incidence of remote $\mathrm{ICH}$ following endovascular treatment of unruptured intracranial aneurysms was $0.46 \%$, which occurred more frequently in patients who received stent-assisted coiling with dual antiplatelet therapy than in those receiving coiling alone with antiplatelet monotherapy. They proposed that changing non-flow-diverting stents to FDs increased the incidence of ICH, suggesting that FD use with dual antiplatelet therapy might play a major role in causing remote $\mathrm{ICH}$.
Another proposed hypothesis for the occurrence of delayed ipsilateral ICH is that exchanging a relatively compliant wall for a rigid stent alters pressure transmission across the segment, ${ }^{3,6}$ reducing the Windkessel effect, ${ }^{6}$ which describes a higher distal pulse pressure due to lower blood vessel elasticity. These changes may cause remote ICHs that arise within the same region as the segment in which the stent is deployed. The Windkessel effect may also be behind the finding that PED-treated patients have an increased risk of remote ICH compared with those receiving standard stent-assisted coiling.

We found that adjunctive coils in the PED group tended to confer a risk of subsequent microbleeds. Adjunctive coils in PED-treated patients have been linked to the formation of new hyperintense lesions on postprocedural DWI, which can in turn lead to hemorrhagic transformation because adjunctive coils require a jailed microcatheter, and the number of microcatheters is strongly associated with DWI abnormalities. ${ }^{32}$ Further studies are needed to determine whether adjunctive coil embolization with PED deployment is correlated with ischemic lesions and hemorrhagic transformation.

This study has several limitations. First, we had a relatively small sample size, which could not provide sufficient power for comprehensive statistical analysis. We therefore did not conduct multivariate logistic regression analysis but were instead restricted to conducting univariate analyses for predictors of microbleeds in the PED group. Further studies are needed to increase the database to allow multivariate analysis in order to better determine independent risk factors for new microbleeds. Second, some of the is- 

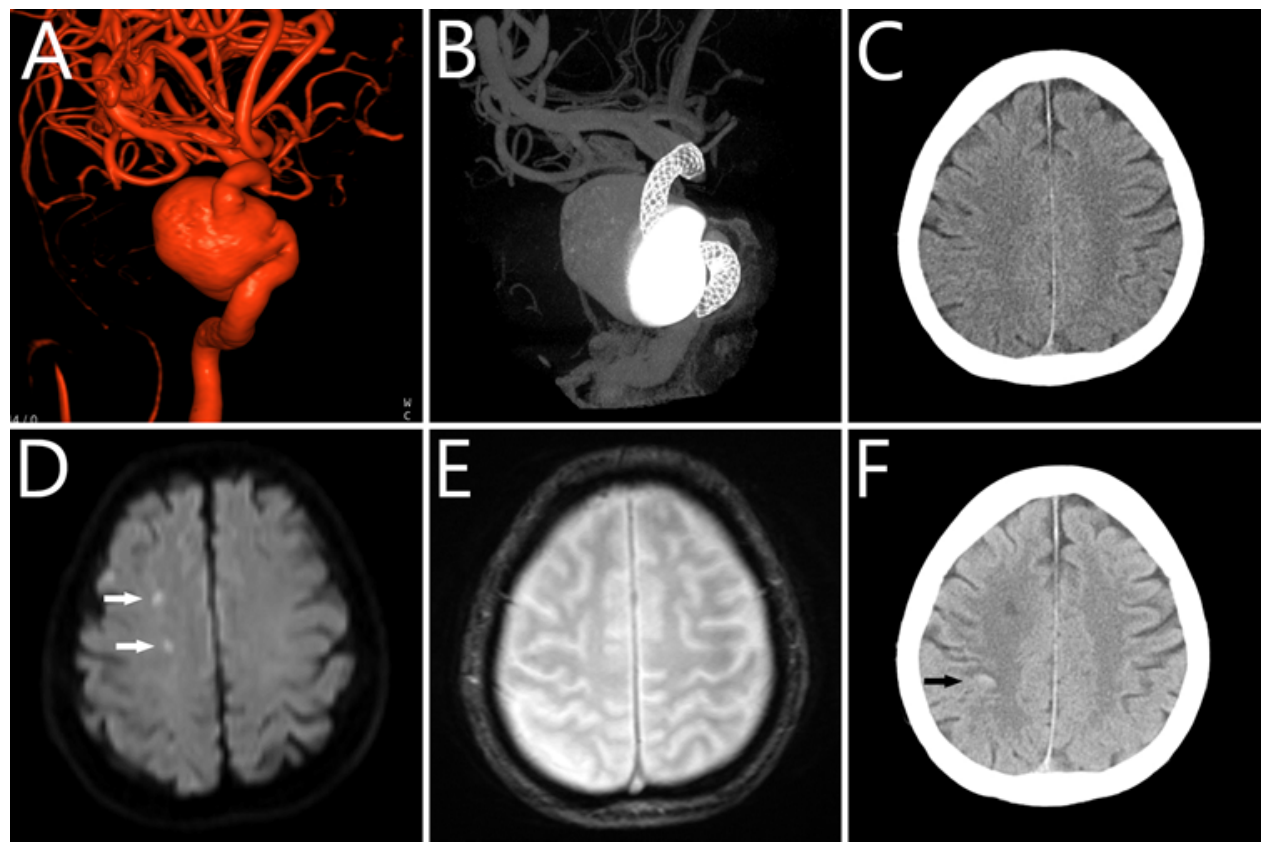

FIG. 4. A: Anterolateral 3D rotational angiogram revealing a large intracranial aneurysm measuring $23.0 \times 14.4 \mathrm{~mm}$ located in the cavernous segment of the right internal carotid artery. B: Multiplanar reconstructed dynamic CT scan with diluted contrast obtained postprocedure, showing the deployed PED traversing the neck of the contrast-filled aneurysm. C: CT scan obtained 1 day postprocedure, revealing no abnormal foci. D: DWI study obtained 1 day postprocedure, revealing hyperintense lesions in the right frontal lobe (arrows). E: T2*WI study obtained 1 day postprocedure, revealing no hypointense lesions. F: CT scan obtained 6 days postprocedure, revealing an intracerebral hemorrhage in the right parietal lobe (arrow), which is distinct from the hyperintense lesions observed on day 1 postprocedural DWI. Panels D and F are reproduced with permission from Nakae R et al: A Pipeline Embolization Device for the treatment of large and giant intracranial aneurysms: initial experience at a single center. JNET 11:359-370, 2017. @2017 The Japanese Society for Neuroendovascular Therapy. CC-BY-NC-ND (https://creativecommons. org/licenses/by-nc-nd/4.0/deed.en). Figure is available in color online only.

chemic lesions on DWI 1 day postprocedure might be associated with the catheter delivery procedure. Third, not all patients underwent MRI between day 1 and 6 months postprocedure. We observed delayed ICH in 2 patients in whom scans were performed at 6 and 7 days postprocedure. It is possible that we might have detected more delayed ICH if we had had all patients undergo MRI at more than one point early in the postoperative period.

\section{Conclusions}

New microbleeds detected on T2*WI 6 months postprocedure were common after PED treatment. The majority of these were hemorrhagic transformations of ischemic lesions that developed 1 day postprocedure. Asymptomatic microbleeds have the potential to become symptomatic ICH. Intraprocedural and postprocedural infarct reduction methods are needed to reduce the risk of hemorrhagic complications following PED placement.

\section{Acknowledgments}

We thank Libby Cone, MD, MA, from DMC Corp. for editing drafts of this manuscript.

\section{References}

1. Becske T, Kallmes DF, Saatci I, McDougall CG, Szikora I, Lanzino G, et al: Pipeline for uncoilable or failed aneurysms: results from a multicenter clinical trial. Radiology 267:858868,2013
2. Bokura H, Saika R, Yamaguchi T, Nagai A, Oguro H, Kobayashi S, et al: Microbleeds are associated with subsequent hemorrhagic and ischemic stroke in healthy elderly individuals. Stroke 42:1867-1871, 2011

3. Brinjikji W, Lanzino G, Cloft HJ, Siddiqui AH, Kallmes DF: Risk factors for hemorrhagic complications following Pipeline Embolization Device treatment of intracranial aneurysms: results from the International Retrospective Study of the Pipeline Embolization Device. AJNR Am J Neuroradiol 36:2308-2313, 2015

4. Chalouhi N, Zanaty M, Jabbour PM, Starke RM, Tjoumakaris SI, Rosenwasser RH, et al: Intracerebral hemorrhage after pipeline embolization: Management of antiplatelet agents and the case for point-of-care testing-case reports and review of literature. Clin Neurol Neurosurg 124:21-24, 2014

5. Chan S, Kartha K, Yoon SS, Desmond DW, Hilal SK: Multifocal hypointense cerebral lesions on gradient-echo MR are associated with chronic hypertension. AJNR Am J Neuroradiol 17:1821-1827, 1996

6. Cruz JP, Chow M, O'Kelly C, Marotta B, Spears J, Montanera W, et al: Delayed ipsilateral parenchymal hemorrhage following flow diversion for the treatment of anterior circulation aneurysms. AJNR Am J Neuroradiol 33:603-608, 2012

7. Delgado Almandoz JE, Crandall BM, Scholz JM, Fease JL, Anderson RE, Kadkhodayan Y, et al: Last-recorded P2Y12 reaction units value is strongly associated with thromboembolic and hemorrhagic complications occurring up to 6 months after treatment in patients with cerebral aneurysms treated with the Pipeline Embolization Device. AJNR Am J Neuroradiol 35:128-135, 2014

8. Delgado Almandoz JE, Crandall BM, Scholz JM, Fease JL, 
Anderson RE, Kadkhodayan Y, et al: Pre-procedure P2Y12 reaction units value predicts perioperative thromboembolic and hemorrhagic complications in patients with cerebral aneurysms treated with the Pipeline Embolization Device. J Neurointerv Surg 5 (Suppl 3):iii3-iii10, 2013

9. Diener HC, Bogousslavsky J, Brass LM, Cimminiello C, Csiba L, Kaste M, et al: Aspirin and clopidogrel compared with clopidogrel alone after recent ischaemic stroke or transient ischaemic attack in high-risk patients (MATCH): randomised, double-blind, placebo-controlled trial. Lancet 364:331-337, 2004

10. Fan YH, Zhang L, Lam WW, Mok VC, Wong KS: Cerebral microbleeds as a risk factor for subsequent intracerebral hemorrhages among patients with acute ischemic stroke. Stroke 34:2459-2462, 2003

11. Fargen KM, Hoh BL: Ipsilateral cerebral hemorrhage following deployment of the Pipeline Embolization Device. J Neurosurg 120:363-364, 2014

12. Greenberg SM, Finklestein SP, Schaefer PW: Petechial hemorrhages accompanying lobar hemorrhage: detection by gradient-echo MRI. Neurology 46:1751-1754, 1996

13. Hahnemann ML, Ringelstein A, Sandalcioglu IE, Goericke S, Moenninghoff C, Wanke I, et al: Silent embolism after stent-assisted coiling of cerebral aneurysms: diffusionweighted MRI study of 75 cases. J Neurointerv Surg 6:461465, 2014

14. Heller RS, Dandamudi V, Lanfranchi M, Malek AM: Effect of antiplatelet therapy on thromboembolism after flow diversion with the Pipeline Embolization Device. J Neurosurg 119:1603-1610, 2013

15. Hu YC, Deshmukh VR, Albuquerque FC, Fiorella D, Nixon RR, Heck DV, et al: Histopathological assessment of fatal ipsilateral intraparenchymal hemorrhages after the treatment of supraclinoid aneurysms with the Pipeline Embolization Device. J Neurosurg 120:365-374, 2014

16. Iosif C, Camilleri Y, Saleme S, Caire F, Yardin C, Ponomarjova $\mathrm{S}$, et al: Diffusion-weighted imaging-detected ischemic lesions associated with flow-diverting stents in intracranial aneurysms: safety, potential mechanisms, clinical outcome, and concerns. J Neurosurg 122:627-636, 2015

17. Kallmes DF, Ding YH, Dai D, Kadirvel R, Lewis DA, Cloft HJ: A second-generation, endoluminal, flow-disrupting device for treatment of saccular aneurysms. AJNR Am J Neuroradiol 30:1153-1158, 2009

18. Kim MS, Jo KI, Yeon JY, Kim JS, Kim KH, Jeon P, et al: Association between postprocedural infarction and antiplatelet drug resistance after coiling for unruptured intracranial aneurysms. AJNR Am J Neuroradiol 37:1099-1105, 2016

19. King B, Vaziri S, Singla A, Fargen KM, Mocco J: Clinical and angiographic outcomes after stent-assisted coiling of cerebral aneurysms with Enterprise and Neuroform stents: a comparative analysis of the literature. J Neurointerv Surg 7:905-909, 2015

20. Kulcsár Z, Houdart E, Bonafé A, Parker G, Millar J, Goddard AJ, et al: Intra-aneurysmal thrombosis as a possible cause of delayed aneurysm rupture after flow-diversion treatment. AJNR Am J Neuroradiol 32:20-25, 2011

21. Kwa VI, Franke CL, Verbeeten B Jr, Stam J: Silent intracerebral microhemorrhages in patients with ischemic stroke. Ann Neurol 44:372-377, 1998

22. Lieber BB, Stancampiano AP, Wakhloo AK: Alteration of hemodynamics in aneurysm models by stenting: influence of stent porosity. Ann Biomed Eng 25:460-469, 1997

23. Nakae R, Suzuki K, Hirata K, Kawamura Y, Suzuki R, Shimizu N, et al: A Pipeline Embolization Device for the treatment of large and giant intracranial aneurysms: Initial experience at a single center. JNET 11:359-370, 2017

24. Nelson PK, Lylyk P, Szikora I, Wetzel SG, Wanke I, Fiorella
D: The pipeline embolization device for the intracranial treatment of aneurysms trial. AJNR Am J Neuroradiol 32:34-40, 2011

25. Nielsen HL, Kristensen SD, Thygesen SS, Mortensen J, Pedersen SB, Grove EL, et al: Aspirin response evaluated by the VerifyNow Aspirin System and light transmission aggregometry. Thromb Res 123:267-273, 2008

26. Nossek E, Chalif DJ, Chakraborty S, Lombardo K, Black KS, Setton A: Concurrent use of the Pipeline Embolization Device and coils for intracranial aneurysms: technique, safety, and efficacy. J Neurosurg 122:904-911, 2015

27. Offenbacher H, Fazekas F, Schmidt R, Koch M, Fazekas G, Kapeller P: MR of cerebral abnormalities concomitant with primary intracerebral hematomas. AJNR Am J Neuroradiol 17:573-578, 1996

28. Safain MG, Roguski M, Heller RS, Malek AM: Flow diverter therapy with the Pipeline Embolization Device is associated with an elevated rate of delayed fluid-attenuated inversion recovery lesions. Stroke 47:789-797, 2016

29. Serebruany VL, Malinin AI, Ferguson JJ, Vahabi J, Atar D, Hennekens CH: Bleeding risks of combination vs. single antiplatelet therapy: a meta-analysis of 18 randomized trials comprising 129,314 patients. Fundam Clin Pharmacol 22:315-321, 2008

30. Shapiro M, Becske T, Sahlein D, Babb J, Nelson PK: Stentsupported aneurysm coiling: a literature survey of treatment and follow-up. AJNR Am J Neuroradiol 33:159-163, 2012

31. Sim SY, Song J, Oh SY, Kim MJ, Lim YC, Park SK, et al: Incidence and characteristics of remote intracerebral hemorrhage after endovascular treatment of unruptured intracranial aneurysms. World Neurosurg 95:335-340, 2016

32. Takigawa T, Suzuki K, Sugiura Y, Suzuki R, Takano I, Shimizu N, et al: Thromboembolic events associated with single balloon-, double balloon-, and stent-assisted coil embolization of asymptomatic unruptured cerebral aneurysms: evaluation with diffusion-weighted MR imaging. Neuroradiology 56:1079-1086, 2014

33. van Swieten JC, Koudstaal PJ, Visser MC, Schouten HJ, van Gijn J: Interobserver agreement for the assessment of handicap in stroke patients. Stroke 19:604-607, 1988

34. Velat GJ, Fargen KM, Lawson MF, Hoh BL, Fiorella D, Mocco J: Delayed intraparenchymal hemorrhage following pipeline embolization device treatment for a giant recanalized ophthalmic aneurysm. J Neurointerv Surg 4:e24, 2012

\section{Disclosures}

The authors report no conflict of interest concerning the materials or methods used in this study or the findings specified in this paper.

\section{Author Contributions}

Conception and design: Nakae. Acquisition of data: Nakae, Kawamura. Analysis and interpretation of data: Nakae, Kawamura. Drafting the article: Nakae. Critically revising the article: all authors. Reviewed submitted version of manuscript: all authors. Approved the final version of the manuscript on behalf of all authors: Nakae. Statistical analysis: Nakae. Administrative/technical/material support: Hyodo. Study supervision: Nakae.

\section{Correspondence}

Ryuta Nakae: Dokkyo Medical University Saitama Medical Center, Saitama, Japan.nakae@nms.ac.jp. 